\title{
OUTRAMENTE QUE SER: REVOLVENDO QUESTÕES À LUZ DA PEDAGOGIA DO OPRIMIDO
}

\author{
Aida Maria Lovison* \\ Guilherme Dornelas Camara**
}

RESUMO - Neste texto, a ética da alteridade de Emmanuel Levinas, para quem a nudez do rosto não é uma figura de estilo, mas a consciência moral, encontra a teoria da ação (cultural) dialógica, fundamento, na pedagogia do oprimido de Paulo Freire, de sua denúncia-anúncio contra a desumanização e a opressão. Para ambos, a violência toma o sentido de posse, modo pelo qual um ente, embora existindo, é parcialmente negado. Essa parcialidade, ao negar a independência do ente, instaura a opressão, negando ao oprimido a sua vocação de ser mais. A opressão mata a vida. Contudo, é pela tomada de consciência desta condição de ser-para-outro, que a própria possibilidade do humano pode ser pensada, porque a relação com outrem ou com a coletividade é nossa relação, irredutível à compreensão. Reconhecer tal subversão, ou seja, que os oprimidos, na medida em que se libertam, eles evitam a volta ao regime opressor e, ao fazê-lo, libertam o opressor, eles inauguram o amor não é assumir, em essência, que ética é a construção do sentido da vida humana desde o encontro com o outro?

PALAVRAS-CHAVE - Humanismo. Liberdade. Ética da alteridade. Pedagogia do oprimido. Transformação social.
ABSTRACT - In this paper, the ethics of otherness of Emmanuel Levinas, for whom the nudity of the Face (visage) is never a matter of style but moral conscience, encounters the theory of (cultural) dialogical action, foundation for Paulo Freire's pedagogy of the oppressed and its denunciation-enunciation of dehumanization and oppression. For both authors, violence gets the meaning of possession, way throughout an entity, although existing, is partially negated. Such partiality, when negating the independence of the entity, states oppression, as it negates the oppressed vocation to be more. Oppression kills life. Whereas, it is through the conscience of such condition of beingfor-other that the proper possibility of humanity can be thought, because the relation to the other or to the collective is our relation, irreducible to understanding. To recognize such subversion, therefore, is to recognize that as the oppressed free themselves, they avoid to get back to an oppressive regime. In doing so, they free their prior oppressors, they inaugurate love. Is it not to assume, in essence, that ethics is a construction of sense of life since the encounter with the Other?

KEY WORDS - Humanism. Freedom. Ethics of otherness. Pedagogy of the oppressed. Social transformation.

\footnotetext{
* Doutora em Sociologia pela Université de Paris VII, Professora do Programa de Pós-Graduação em Administração/UFRGS.

** Mestre em Administração pela UFRGS.
}

\begin{tabular}{l|l|l|l|l|l} 
VERITAS & Porto Alegre & v. 53 & n. 2 & abr./jun. 2008 & p. 7-17
\end{tabular}


Como posso aparecer para mim mesmo como rosto? Quais são as condições da aparição do rosto, quer dizer, da tentação e da impossibilidade do homicídio? Podem as coisas tomar um rosto? Ora, o rosto - cuja nudez não é uma figura de estilo, mas a consciência moral, significa outramente. Deixarser o ente, compreendê-lo como independente da percepção que o descobre e o apreende significa que aquele a quem se fala é compreendido no seu ser. A questão na nossa relação com o Outro será deixá-lo ser (LEVINAS, 2005, p. 27)? De forma alguma. Outrem não é primeiro objeto de compreensão e, depois, interlocutor. As duas relações confundem-se, [pois], da compreensão de outrem é inseparável a sua invocação (LEVINAS, 2005, p. 27). No rosto do outro a infinita resistência do ente ao nosso poder se afirma precisamente contra a vontade assassina que ela desafia, porque totalmente nua - e a nudez do rosto não é uma figura de estilo, ela significa por si mesma. Em que medida a relação com outrem ou com a coletividade é nossa relação, irredutível à compreensão, com o infinito?

Compreender uma pessoa é falar-lhe. Por a existência de outrem, deixando-a ser, é já ter aceito essa existência, tê-la tomado em consideração e isso não corresponde a uma compreensão, a um deixar-ser. "O Outro aquele que chega de fora - fora âmbito do meu poder intelectual, de minha inteligência que vê e avalia o mundo - ele chega sempre inesperadamente: dá-se sem que eu possa, sem mais, anular essa sua presença e esse seu sentido (SOUZA, 2004, p. 56). Noutras palavras, o Outro não se reduz a uma representação, ele surge como a pré-sença de algo, como uma condição desta "tomada de consciência" porque o acontecimento da linguagem não se situa mais sobre o plano da compreensão. Por que com base neste acontecimento não alargar a noção se compreensão segundo o procedimento que se tornou familiar pela fenomenologia onde a invocação de outrem é apresentada como característica da própria compreensão? "Aqui a fórmula 'antes de estar em relação com um ser é preciso que eu o tenha compreendido como ser' perde a sua aplicação estrita: ao compreender o ser, digo-lhe simultaneamente minha compreensão" (LEVINAS, 2005, p. 28).

Esta impossibilidade de abordar outrem sem lhe falar mostra que o pensamento funciona pelo processo de redução do Outro ao Mesmo - em termos de sínteses ou de classificações que fazemos constantemente, mas que tal lógica é aqui interrompida, porque o pensar, o Eu que pensa, encontrou alguém, alguém que pode dizer "não" ao meu "sim": alguém que se nega a algum tipo de explicação de sua existência, de sua presença, por alguma via lógica ou classificatória. No fundo, permanece este Outro em si, e, não obstante, está suficientemente próximo de mim para me obrigar a perceber sua existência como absolutamente real (SOUZA, 2004, p. 57).

A base desta sociabilidade que não é ontologia, quer dizer, onde o vínculo com outrem não se reduz à representação de outrem, mas a sua invocação, e onde a invocação não é precedida de compreensão Levinas chama-a religião. A essência do discurso é, para ele, oração. A oração por sua vez é 
a declaração de uma impossibilidade de uma representação, pois a razão dominação, feita para as coisas, foi superada, posto que exige renúncia. "Inteligência como ardil, inteligência como inteligência da luta e da violência, feita para a coisas - estará ela em condições de constituir uma ordem humana"?, questiona Levinas (2005, p. 30).

O que distingue o pensamento que visa a um objeto de um vínculo com uma pessoa é que neste se articula um vocativo: o que é nomeado e, ao mesmo tempo, aquele que é chamado. O paradoxo, para Levinas (2005, p. 30), é que por força do hábito fomos condicionados "a procurar na luta a própria manifestação do espírito e da sua realidade. Mas a ordem da razão não se constitui antes numa situação em que 'se fala', em que a resistência do ente, enquanto ente, não é quebrada mas pacificada"? Quer dizer, o Outro que está minha frente não é apenas um problema teórico, mas um acontecimento concreto, que desestabiliza as certezas da minha inteligência. Eu não posso, de forma alguma, determinar aquilo que o Outro é enquanto tal. Não se trata tão pouco de opor uma essência à outra, ou seja, contentarse em opor o inerte ao dinamismo, à transcendência ou à liberdade, para dizer o que é a essência do homem. "Trata-se, antes de tudo, de encontrar para ele o lugar por onde ele cessa de nos concernir a partir do horizonte do ser, isto é, de se oferecer aos nossos poderes. [...] E é enquanto próximo que o homem é acessível. Enquanto rosto (LEVINAS, 2005, p. 30).

Este encontro com o Outro - ou melhor, a possibilidade deste - não vai ser uma questão teórica, já que neste caso recairíamos novamente no campo da representação mental, no campo da idéia de "outro" que já temos - mas uma questão fundamentalmente ética, prática, pois se trata do Outro concreto que encontramos, e não uma imagem dele. Nomear é compreender sem invocar, isto é, conferir a outrem uma significação a partir do ser. Esta parcialidade que é simultaneamente uma negação e uma violência, consolida-se no fato de que o ente, sem desaparecer, se encontra em meu poder. Este ato de parcialidade nega a independência do ente: ele depende de mim.

A posse é o modo pelo qual um ente, embora existindo, é parcialmente negado. Não se trata apenas do fato de o ente ser instrumento e utensílio quer dizer meio; ele é também fim - consumível, é alimento e, no gozo, se oferece, se dá, depende de mim. A visão, com certeza, mede o meu poder sobre o objeto, mas ele já é gozo. O encontro com outrem consiste no fato de que, apesar da extensão da minha dominação sobre ele e de sua submissão, não o possuo. Ele não entra inteiramente na abertura do ser que já me encontro como no campo de minha liberdade. Não é a partir do ser em geral que ele vem ao meu encontro. Compreendo-o a partir da sua história, do seu meio, dos seus hábitos. Não posso negá-lo parcialmente, na violência, apreendendo-o a partir do ser e possuindo-o. Outrem é o único ente cuja negação não pode anunciar-se senão como total: um suicídio. Outrem é o único ser que posso querer matar (LEVINAS, 2005, p. 31). 
O triunfo deste poder - que eu posso querer - é totalmente o contrário do poder, é sua derrota como poder, pois:

No momento em que meu poder de matar se realiza, o outro se me escapou. Posso, é claro, ao matar, atingir o meu objetivo, posso matar, como faço uma caçada o como derrubo uma árvore ou abato animais, mas neste caso, apreendi o outro na abertura do ser em geral, como elemento do mundo em que me encontro, vislumbrei-o no horizonte. Não o olhei no rosto, não encontrei seu rosto. A tentação da negação total, medindo o infinito desta tentativa e sua impossibilidade, é a presença do rosto. Estar em relação com o outrem face a face - é não poder matar. E também a situação do discurso (LEVINAS, 2005, p. 32).

À compreensão e à significação, tomadas a partir do horizonte, Levinas opõe a significação do rosto. Ou seja, ao nomear as coisas como coisas, meros entes, a relação com elas se institui como compreensão, solapando o face-a-face. Quem lhes empresta a significação não é o rosto, mas a totalidade. A palavra, fundamento da relação com o outro, está ausente, fica suprimida, lateralizada. Como entender então essa proposta levinasiana de um dar-se que adquire significação a partir daquilo que não se é?

\begin{abstract}
A relação com o rosto, acontecimento da coletividade - a palavra - é relação com o próprio ente, enquanto puro ente. Que a relação com o ente seja invocação do rosto e já palavra, [...] que meu próximo seja o ente por excelência, tudo isso parece assaz surpreendente. O rosto significa outramente. Nele, a infinita resistência do ente ao nosso poder se afirma precisamente contra a vontade assassina que ela desafia, porque totalmente nua [...] (LEVINAS, 2005, p. 32, grifos nossos).
\end{abstract}

Em tais circunstâncias podem as coisas tomar um rosto? A arte não é uma atividade que confere rosto às coisas? A fachada da casa não é uma casa que nos olha? A rigor, a única coisa que posso ousar dizer a respeito deste Outro é determinado justamente por ele: que ele é de outro modo outramente - que eu, ou seja, que entre nós uma verdadeira e irredutível diferença tem lugar (SOUZA, 2004, p. 57). Este é o Outro de quem eu posso dizer apenas o que eu consigo captar dele, dele perceber e classificar, que pode dizer "não" ao meu "sim", e ao qual perguntamos seu nome chama-se "encontro". A reflexão filosófica não obstante dá-nos apenas o relato da aventura pessoal, da alma privada, que retorna incessantemente a si mesma, até quando parece fugir de si. "O humano só se oferece a uma relação que não é poder" (LEVINAS, 2005, p. 33). Ora, não está aqui o núcleo originário, a essência da racionalidade ética? Estar disponível ao ainda não-conhecido, esta situação de insegurança, de mero aparecer da Alteridade, do inusitado, do traumático não remete gordianamente a esta vinculação íntima entre a ética e a política? Se a ética é a própria possibilidade de pensar o humano, o seu significado parece ser o seguinte: "ética é a construção do sentido da vida humana desde o encontro com o outro" (SOUZA, 2004, p. 56).

Ser humano é provir e viver na multiplicidade do humano e este viver, em todos os momentos de nossa vida, define-se na sua especificidade única 
e não neutra de cada ato. Um ato isolado tanto pode fazer viver como fazer morrer. Porém a materialização desta verdade não se dá claramente em todo ou em cada um dos instantes da existência, pois:

Não há instante isolado, neutro ou indiferente para a vida; há apenas instantes que conspiram, ou para a continuação e promoção da vida, ou para sua corrosão e destruição. E isto por um motivo muito simples: o ser humano é um ser não-neutro por excelência. Essa não neutralidade é simultaneamente, em termos filosóficos, o resultado da reflexão original sobre a condição humana e a possibilidade de tal reflexão (SOUZA, 2004, p. 20).

Aliás, no Julgamento de Eichmann em Jerusalém ${ }^{1}$ o que deixou Hannah Arendt (2004) impressionada foi isto que ela chama de banalidade, ou seja, a total falta de espontaneidade, a qual não tornava Eichmann nem um "mostro" nem um "demônio", mas ainda assim um agente do mal mais extremo. Por meio dessa obra ela analisa o mal da dominação totalitária do século XX, mas o que a própria Arendt não percebera antes de defrontar-se com a incapacidade de Eichmann de refletir sobre os seus atos - o que ela distinguia de estupidez -, é que esse mal podia se espalhar ilimitadamente pela Terra, e o seu aspecto mais surpreendente era que a sua expansão não precisava estar arraigada numa ideologia. O mal humano é ilimitado quando não gera nenhum remorso, quando os atos são esquecidos assim que são cometidos. Segundo Arendt (2004, p. 26), há um preço a ser pago por sermos livres, por esta liberdade que temos de experimentar a liberdade como começo. "A contingência da liberdade humana é a crise real que vivemos hoje; não pode ser evitada, e a única questão significativa que pode ser proposta é se a nossa liberdade nos agrada ou não, se estamos ou não dispostos a pagar o seu preço". "O Outro é o único ser que não posso encontrar sem lhe exprimir este encontro mesmo" (LEVINAS, 2005, p. 28). Ou, como diria Freire (1988, p. 143) Esse processo de libertação, liberdade constituída de eticicidade, requer entretanto uma pedagogia.

\section{O outro e/na pedagogia do oprimido}

Ao confrontar-se com o problema da desumanização, Paulo Freire (1988 [1970, p. 30) é enfático: "A pedagogia dominante é a pedagogia das classes

1 Eichmann em Jerusalém - É um Relato da banalidade do mal - publicado em 1963 por Hannah Arendt, que nasceu judia-alemã, cujo foco é o esvaziamento burocrático do juízo e da moral individuais diante da carnificina nazista. Este fenômeno que ela captou na célebre fórmula sobre a "banalidade do mal" - e que vê alastrar-se em fatos como a invenção da bomba atômica e seu emprego para destruir Hiroshima e Nagasaki na Segunda Guerra Mundial; mais adiante a Guerra Fria e a capacidade sem precedentes de o mundo pós-totalitário destruir a si próprio com armas nucleares; a Guerra da Coréia e mais adiante a do Vietnã; acontecimentos que podem ser vistos em termos de colapso da moralidade - a inquieta, (morreu em 1975), dedicando-se posteriormente a estudá-lo, dado o seu possível alastramento nas sociedade contemporâneas. 
dominantes. Os métodos da opressão não podem, contraditoriamente, servir à libertação do oprimido". A violência, a vida lhe mostrou, é um processo que passa de geração em geração. E é sobretudo a partir dessa dolorosa constatação que nega aos oprimidos a vocação de ser mais, que os homens se perguntam sobre a outra viabilidade - a humanização.

Mas, se ambas são possibilidades, só a primeira parece ser o que chamamos de a vocação dos homens. Vocação negada mas também afirmada na própria negação. Vocação negada na injustiça, na exploração, na opressão, na violência dos opressores. Mas afirmada no anseio de liberdade, de justiça, de luta dos oprimidos pela recuperação de sua humanidade roubada (FREIRE, 1988, p. 30).

Ora, "a opressão só existe quando se constitui em um ato proibitivo do ser mais dos homens" (FREIRE, 1988, p. 44). Assim, à medida que os oprimidos se libertam, eles evitam a volta ao regime opressor e, ao fazê-lo, libertam o opressor, eles inauguram o amor.

Os opressores não amam, porque apenas se amam. [...] Os opressores, violentando e proibindo que os outros sejam, não podem igualmente ser; os oprimidos, lutando por ser, ao retirar-lhes o poder de oprimir e esmagar, lhes restauram a humanidade que haviam perdido na opressão. [...] a superação autêntica da contradição opressores-oprimidos não está [portanto] na pura troca de lugar, na passagem de um pólo a outro. Mais ainda: não está em que os oprimidos de hoje, em nome de sua libertação, passem a ter novos opressores" (FREIRE, 1988, p. 43; 44, grifo nosso).

Com efeito, a reconstrução em termos autênticos da sociedade, não é um processo mecanístico, mas um processo que tem na cultura que culturalmente se refaz, o seu instrumento fundamental. Por isto mesmo é que este esforço educativo-pedagógico transformador não se pode contentar com a formação tecnicista dos técnicos, nem cientificista dos cientistas, necessários à nova sociedade. Isso exige, de um ponto de vista ético, uma outra lógica que a lógica da inteligência, perspectiva segundo a qual o mundo pode ser pensado desde a articulação pura e simples de interesses de poder.

Não é igualmente possível à sociedade que culturalmente se refaz atribuir à tecnologia as mesmas finalidades que lhe eram atribuídas pela sociedade anterior. Conseqüentemente, nela varia, igualmente a formação dos homens. Nesse sentido, a formação técnico-científica não é antagônica à formação humanista dos homens, desde que ciência e tecnologia, na sociedade em reconstrução, sejam postas a serviço da libertação permanente, de sua humanização. Neste processo, finalmente, a revolução, desenvolvendo a prática do diálogo permanente entre os agentes inseridos numa localidade específica, consolida a participação destes no poder. Desta forma, explica Freire (1988) uns e outros vão se criticizando, defendendo-se dos riscos dos burocratismos que implicam novas formas de opressão e "invasão", que são sempre as mesmas: Seja o invasor um agrônomo extensionista - numa sociedade burguesa ou numa sociedade revolucionária -, um investigador 
social, um economista, um sanitarista, um religioso, um educador popular, um assistente social ou um revolucionário que, em sendo invasivo, se contradiz.

Na visão do autor, a invasão cultural (grifo do autor), que serve à conquista e à manutenção da opressão, implica sempre a visão focal da realidade, a percepção desta como estática, a superposição de uma visão do mundo na outra. A "superioridade" do invasor, a "inferioridade" do invadido; à imposição dos critérios e à posse do invadido, o medo de perdê-lo. Em tal processo, o ponto de decisão da ação dos invadidos está fora deles e nos dominadores invasores. Ora, "Enquanto a decisão não está em quem deve decidir, mas fora dele, este apenas tem a ilusão de que decide. Esta é a razão por que não pode haver desenvolvimento sócio-econômico em nenhuma sociedade dual, reflexa, invadida" (FREIRE, 1988, p. 158). É que, para haver desenvolvimento, é necessário: que haja um movimento de busca, de criatividade que tenha, no ser mesmo que o faz, o seu ponto de decisão; que esse movimento se dê não só no espaço, mas no tempo próprio ser, do qual tenha consciência. Daí que todo desenvolvimento é transformação, mas nem toda transformação é desenvolvimento.

Ademais, o ser humano é, dentre os seres inconclusos, como a transformação do ser de um animal e que não é desenvolvimento, o único que se transforma autenticamente. Submetido a condições de opressão ela já não se desenvolve autenticamente. Esta é a razão pela qual, submetidos a condições concretas de opressão em que se alienam, transformados em seres para outro do falso ser para si de quem dependem, os homens já não se desenvolvem autenticamente. É que, assim roubados na sua decisão, que se encontra no ser dominador, seguem suas prescrições. Em suma, propõe Freire (1988), os oprimidos só começam a desenvolver-se, quando, superando a contradição em que se acham, se fazem seres-para-si. Isso que vale para os seres humanos em sum sentido adverbial também bale substantivamente para a sociedade, quer dizer, uma sociedade dual é uma sociedade modernizada: não é sociedade desenvolvida.

Somente uma sociedade "ser-para-si", uma sociedade livre, poderá desenvolver-se. Mas [...] é preciso não confundir desenvolvimento com modernização. Uma sociedade simplesmente modernizada, mas não desenvolvida, continua dependente do centro externo, mesmo que assuma, por mera delegação, algumas áreas mínimas de decisão" (FREIRE, 1988, p. 156; 159).

O autor está convencido de que, para aferirmos se uma sociedade se desenvolve ou não, devemos ultrapassar os critérios que se fixam na análise de seus índices per capita de ingresso que, 'estatisticados', não chegam sequer a expressar a verdade, bem como os que se centram no estudo de sua renda bruta. O critério básico, primordial, está em sabermos se a sociedade é ou não é um "ser-para-si", ou seja, em sabermos se a dualidade existencial dos oprimidos que, hospedando o opressor, cuja sombra eles 
introjetam, tornando-os eles e ao mesmo tempo em que são o outro, foi desanuviada. Se a resposta é não, todos estes critérios indicarão que esta sociedade é uma sociedade modernizada, produziu estilos de vida, mas não seu desenvolvimento.

Diante disso, como pensar a sociedade brasileira, hoje? Chegará ela a atingir uma condição de sociedade desenvolvida ou permanecerá neste ethos de uma sociedade modernizada, mesclando zonas de riqueza com bolsões de pobreza e miséria absoluta? A contradição principal nas sociedades duais é, realmente, esta - a das relações de dependência que se estabelecem entre elas e a sociedade metropolitana. Se esta contradição, ou melhor essa dualidade não for superada, essas sociedades "não são seres-para-si" e, não o sendo, não se desenvolvem. A crise do humanismo, nos dias atuais, "não tem sua fonte na experiência da ineficácia humana posta em acusação pela própria abundância de nossos meios de agir e pela extensão de nossas ambições"? (LEVINAS, 1993, p. 82).

[Nestas sociedades duais], uma adesão aos oprimidos, ela implicita, quando verdadeira, um ato de amor, de real compromisso" (FREIRE, 1988, p.160, grifos nossos). O que importa, nesse sentido, é que a liderança caminhe até eles, gerando as condições que lhes permita, em comunhão com eles, de saber-se em antagonismo com ela, sem a qual a postura de "adesão" e/ ou de "aderência" ao opressor não é possível de ser rompida. É possível também que face a essa tensão consciência-mundo, em virtude de certas condições históricas objetivas, os oprimidos já tenham chegado, senão à visualização clara de sua opressão, a uma quase "claridade" desta. "Se, no primeiro caso, a sua aderência ou 'quase aderência' ao opressor não lhes possibilita localizá-lo fora delas, no segundo, localizando-o, se reconhecem, em nível crítico, em antagonismo com ele" (FREIRE, 1988, p. 151-152). No primeiro caso, explica Freire, com o opressor hospedado nelas, a sua ambigüidade as faz mais temerosas da liberdade. Apelam para explicações mágicas ou para um visão falsa de Deus (estimulada pelos opressores), a quem fatalisticamente transferem a responsabilidade de seu estado de oprimidos. No segundo caso, com o alcance de uma relativa "clareza" ou uma quase "clareza" da opressão, o que as leva a localizar o opressor fora delas, aceitam a luta para superar a contradição em que estão. Nesse momento, superam a distância que medeia as objetivas "necessidades de classe" da "consciência de classe". De forma distinta, esta segunda possibilidade supõe um engajamento ativo e crítico na superação das contradições. O caminho que, neste caso, a liderança faz até as massas é espontaneamente dialógico e está a exigir dela uma teoria:

\section{A teoria da ação (cultural) dialógica ou a dialética eu-tu}

A teoria da ação (cultural) dialógica tem na relação dialética eu-tu seu fundamento constitutivo. $\mathrm{E}$ a dialogicidade, por sua vez, é a essência da educação como prática da liberdade, via instauradora da alteridade como 
fundamento da vida ética. Assim, "enquanto na ação antidialógica a conquista, como sua primeira característica, implica um sujeito que, conquistando o outro, o transforma em quase 'coisa', na teoria dialógica da ação, os sujeitos se encontram para a transformação do mundo, em colaboração" (FREIRE, 1988, p. 165).

$\mathrm{O}$ eu antidialógico, dominador, transforma o tu dominado, conquistado, num mero "isto". O eu dialógico, pelo contrário, sabe que é exatamente o tu que o constitui ao ter no seu eu um tu (FREIRE, 1988, p. 165). O eu sabe também que esse tu - um não-ser - que o constitui se constitui, por sua vez, como eu ao ter acesso ao tu. Na dialética destas relações constitutivas, o eu e o tu passam a ser dois tu que se fazem dois eu. "Não há, portanto, na teoria dialógica da ação, um sujeito que domina pela conquista e um objeto dominado. Em lugar disto, há sujeitos que se encontram para a pronúncia do mundo, para a sua transformação" (FREIRE, 1988, p. 165).

A co-laboração, por sua vez, como característica da ação dialógica, que não pode dar-se a não ser entre sujeitos, ainda que tenha níveis distintos de função, portanto de responsabilidade, somente pode realizar-se na comunicação. O diálogo, que é sempre comunicação, funda a co-laboração. Na teoria da ação dialógica, não há lugar para a conquista das massas aos ideais revolucionários, mas para a sua adesão.

No espírito de Paulo Freire, materializado em sua práxis pedagógica, o diálogo não impõe, não maneja, não domestica, não sloganiza. Não significa isto que teoria da ação dialógica conduza ao nada: ela tem um compromisso com a liberdade das massas oprimidas, para que se libertem com base na sua adesão. Para ele, adesão conquistada não é adesão, porque é "aderência" do conquistado ao conquistador através da prescrição das opções deste àquele. A adesão verdadeira é a coincidência livre se opõem e esta não pode verificar-se a não ser na intercomunicação dos homens, mediatizados pela realidade. Daí que, ao contrário do que ocorre com a conquista, na colaboração, exigida pela teoria dialógica da ação, os sujeitos dialógicos se voltam sobre a realidade mediatizadora que, problematizada, os desafia.

A resposta aos desafios da realidade problematizada é já a ação dos sujeitos dialógicos sobre ela, para transformá-la. Problematizar, mais uma vez, não é sloganizar, é exercer uma análise crítica sobre a realidade problema. Há, portanto, que chegar às causas dos problemas como a miséria e a injustiça em suas manifestações e seus sintomas e há que fazê-lo com suas vítimas a fim de buscar a libertação dos homens em co-laboração com eles. [...] Acontece que paz não se compra, se vive no ato realmente solidário, amoroso, e este não pode ser assumido, encarnado, na opressão" (FREIRE, 1988, p. 143).

\section{À guisa de conclusão}

Como pensar a Alteridade à luz da Pedagogia do Oprimido, ou seja, quando a consciência é habitada pela ambígua intrusão do opressor, 
interpondo-se à possibilidade do oprimido tornar-se um sujeito, um "serpara-si"? Com pensar hoje esta superação enquanto esta é condição para se erigir uma sociedade desenvolvida? Se a adesão verdadeira é a coincidência livre se opõem e esta não pode verificar-se a não ser na intercomunicação dos homens, mediatizados pela realidade, como um ser destituído da sua diferença poderá ousar assumir ou dizer a respeito deste Outro que ele, Outro, é determinado justamente por ele, em suma, que ele é de outro modo-outramente - que eu e que entre eu e tu uma verdadeira e irredutível diferença tem lugar? Se as coisas são apenas coisas, sem rosto, porque a relação com elas se institui como compreensão, e não como aparição do rosto, como se dará a audição desta dissonância levinasiana de que o humano só se oferece a uma relação que não é poder?

Se a ética é relação e relação com o outro, com a alteridade e, nessa medida impensável fora de um lugar de sua realização, como pensá-la então no bojo da dialética opressor-oprimido? É possível no interior da estrutura de finitude na qual vivemos, superar o ardil da inteligência que institui a relação como compreensão, e no face-a-face conceber a possibilidade da própria alteridade?

A teoria da ação cultural dialógica propõe ir à causa dos problemas, sem sloganizar. A resposta aos desafios da realidade problematizada é já a ação dos sujeitos dialógicos sobre ela, para transformá-la Nesta, os sujeitos dialógicos se voltam sobre a realidade mediatizadora que, problematizada, os desafia. Aqui, na substantividade do estar com, parece, encontra-se um caminho profícuo para a Ética da Alteridade, ou seja, uma forma de pensar a realidade desde a justiça: "justiça em todos os sentidos, justiça para com o que não é nós, justiça para nós como justiça para com o outro que nós" (SOUZA, 2004, p. 51). Ou seja, o encontro com a alteridade radical se efetiva no tempo que nós mesmos somos e em que cada instante é um instante de decisão - de decisão pela justiça ou pela injustiça. Por isso, oração, esta declaração da impossibilidade da representação, E pensar a alteridade do ponto de vista do trauma pela injustiça cometida é colocá-la como fundamento da nossa indignação, do insuportável que, ao trazer a nossa consciência a consciência da precariedade da existência, nos interdita a paz; é buscar dissolver a indiferença colocando a questão da justiça como fundamento da estrutura das relações humanas (SOUZA, 2004, p. 50).

A crise do humanismo na contemporaneidade tem sua fonte, sem dúvida, para Levinas (1993, p. 82), "na experiência da ineficácia humana posta em acusação pela própria abundância de nossos meios de agir e pela extensão de nossas ambições". Assim, a concepção de justiça enquanto fundamento de qualquer realidade só se efetiva na temporalidade real na qual a justiça real pode ser efetivada; temporalidade que é expressão de alteridade e que, por levar o Outro a sério, já é alteridade. Porquanto "se nada ficar destas páginas, pelo menos, esperamos que permaneça: nossa confiança no povo. Nossa fé nos homens e na criação de um mundo em que seja menos difícil amar". (Paulo Freire, A Pedagogia do Oprimido (1988, [1970], p. 184). 


\section{Referências}

ARENDT, H. Julgamento e responsabilidade. São Paulo: Companhia das Letras, 2004.

FREIRE, P. A pedagogia do oprimido. 18. ed. Rio de Janeiro: Paz e Terra, 1988.

. À sombra da mangueira. 8. ed. São Paulo: Olho d'Água, 2006.

LEVINAS, E. Entre nós: Ensaios sobre a alteridade. 2. ed. Petrópolis, RJ: Vozes, 2005.

Humanismo do outro homem. Petrópolis, RJ: Vozes, 1993.

SOUZA, R. T. de. Justiça, liberdade e alteridade ética. Sobre a questão da radicalidade da justiça desde o pensamento de E. Levinas. In: OLIVEIRA, Nythamar Fernandes de; SOUZA, Draiton Gonzaga de. Justiça e política: homenagem a Otfried Höffe. Porto Alegre: EDIPUCRS, 2003. p. 619-633.

. Ética como fundamento: uma introdução à ética contemporânea. São Leopoldo: Nova Harmonia, 2004. 